\title{
latrogenic left anterior descending artery stenosis early after aortic valve replacement presenting with T-wave-pseudonormalization - a case report
}

\author{
Stefan Schwarz ${ }^{1 *}$, Hermann Blessberger ${ }^{1}$, Jürgen Kammler ${ }^{1}$, Christoph Gross $^{2}$ and Clemens Steinwender $^{1}$
}

\begin{abstract}
Background: Both iatrogenic coronary artery stenosis early after aortic valve replacement and pseudonormalization of inverted T-waves in acute ischemia are rare but well-recognized findings which coincide in this case.

Case presentation: 10 weeks after aortic valve replacement, a 58-year-old male patient was readmitted with recent onset of unstable angina pectoris. Electrocardiography showed inverted T-waves in leads V2-4 with pseudonormalization during episodes of typical chest pain. Coronary angiography revealed subtotal ostial occlusion of the left anterior descending artery which was successfully treated by percutaneous coronary intervention.

Conclusion: latrogenic coronary artery stenosis is a potentially life-threatening complication that can occur early after aortic valve replacement in patients with normal preoperative coronary angiography. T-wave-pseudonormalization during episodes of angina pectoris may lead to misinterpretation in patients at high risk.
\end{abstract}

Keywords: latrogenic coronary artery stenosis, Aortic valve replacement, Pseudonormalization, Percutaneous coronary intervention

\section{Background}

Pseudonormalization of abnormal T-waves in spontaneous or provoked ischemia was first described by Noble et al. [1]. The underlying electrophysiological mechanism generally thought to apply is a superposition of acute ischaemic effects on the action potential of subepicardial cells on top of chronic ischaemic effects [2]. Among other probable causes, $\mathrm{T}$-wave inversion in the anterior precordial leads usually reflects severe left anterior descending coronary artery stenosis [3]. Development of angina pectoris within a few months after aortic valve replacement is highly suspicious for iatrogenic proximal coronary artery stenosis [4]. These two rare findings of clinical cardiology coincide in this case.

\section{Case presentation}

We report the case of a 58-year-old male patient undergoing valve replacement surgery for symptomatic aortic valve stenosis. Coronary heart disease had been ruled

\footnotetext{
* Correspondence: stefan.schwarz@akh.linz.at

${ }^{1} 1$ st Medical Department - Cardiology, Linz General Hospital, Johannes Kepler University School of Medicine, Krankenhausstrasse 9, 4020 Linz, Austria Full list of author information is available at the end of the article
}

out preoperatively by coronary angiography. Valve replacement surgery was performed using a St. Jude 25 $\mathrm{mm}$ mechanical valve prosthesis (St. Jude Medical Inc., St. Paul, MN, USA). During surgery, cardioplegic solution was administered by selective antegrade ostial cannulation using a $3 \mathrm{~mm}$ coronary artery perfusion cannula with a $6 \mathrm{~mm}$ balloon tip (CalMed Laboratories, Costa Mesa, CA, USA). Postoperative recovery and rehabilitation were unremarkable without symptoms of angina pectoris.

10 weeks after surgery, the patient was readmitted to our department with recent onset of unstable angina. Oral anticoagulation with phenprocoumon was within therapeutic range with an INR value of 2,7 (target median INR 2,5 in case of low prosthesis thrombogenicity and no patient-related risk factors). Baseline ECG on admission was recorded while the patient was free of symptoms and showed symmetrical negative $\mathrm{T}$-waves in leads V2-4 (Figure 1). Echocardiographic evaluation showed good prosthetic valve function and a normal left ventricular ejection fraction without abnormal regional wall motions. 


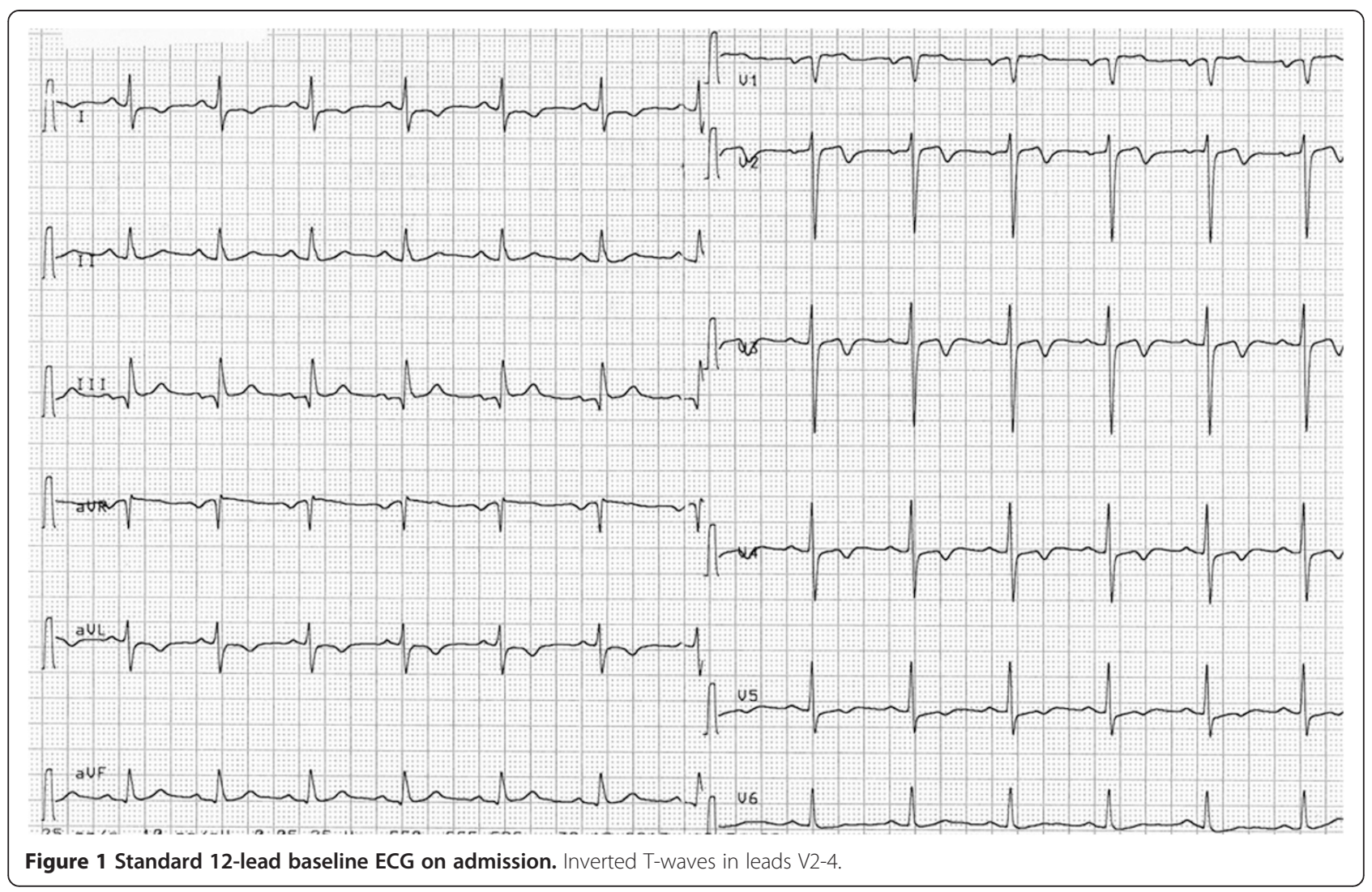

Recurrent severe attacks of angina pectoris at rest were successfully treated with morphine and glyceryl trinitrate. Simultaneous ECG recordings showed normalization of the previously inverted T-waves (Figure 2). Despite serial negative measurement of cardiac markers including high sensitive troponin $\mathrm{T}$, loading doses of $250 \mathrm{mg}$ acetylsalicylic acid and $300 \mathrm{mg}$ clopidogrel were administered upon these findings and an early invasive strategy was planned.

Coronary angiography revealed subtotal ostial occlusion of the left anterior descending artery (Figure 3) and successful percutaneous coronary intervention was performed using a Zotarolimus-eluting stent (Resolute Integrity $3,0 \times 12 \mathrm{~mm}$, Medtronic Inc., Minneapolis, MN, USA) (Figure 4). Antiplatelet therapy will comprise three months of dual antiplatelet therapy (acetylsalicylic acid and clopidogrel) followed by nine months of single antiplatelet therapy (acetylsalicylic acid alone), combined with unaltered continuation of phenprocoumon.

\section{Discussion}

Data concerning the incidence of pseudonormalization in acute coronary syndrome are scarce. In one large perennial single-center survey it was $1 \%$ and typically caused by severe coronary artery stenosis lacking coronary collateral development [5]. Pseudonormalization can also occur in the setting of coronary angioplasty, where iatrogenic transient coronary occlusion can serve as a model for understanding acute myocardial ischemia [6]. The electrophysiological basis of T-wave pseudonormalization is the following: chronic ischaemic injury of subepicardial cells causes a longer duration of the action potential than in subendocardial cells and therefore a negative $T$ wave. Pseudonormalization can be seen when acute ischaemic injury in subepicardial cells with previous chronic ischaemic injury will progressively shorten the duration of the action potential compared to subendocardial cells, resulting in an iso-electric or positive T-wave [2]. Knowledge and understanding of this phenomenon should lead to serial ECG recording in patients with typical presentation of unstable angina pectoris.

Iatrogenic coronary artery stenosis (ICAS) occurs after 1 to $5 \%$ of aortic valve replacement procedures and the clinical symptoms are usually typical, severe, and appear within the first 6 months following surgery $[7,8]$. In most cases, the left main stem or the ostium of the right coronary artery are affected, although stenosis of the ostium of the left anterior descending artery has also been reported [9]. Selective antegrade ostial cannulation for administration of cardioplegic solution during surgery is generally thought to cause an initial mechanical vessel wall trauma. Multidetector computed tomography and optical coherence tomography identified fibrous tissue formation and intimal hyperplasia in ICAS, which therefore differs 


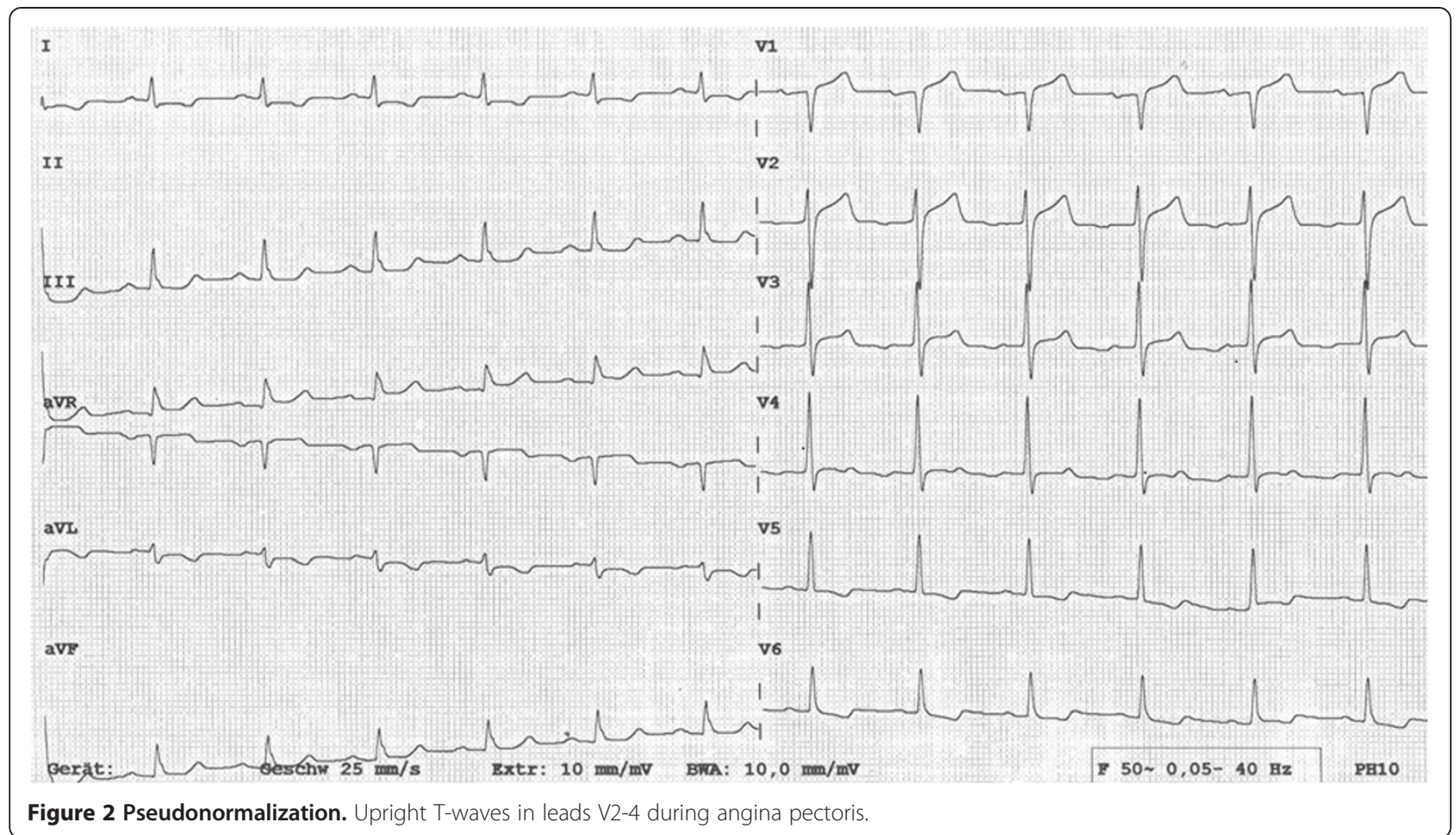

pathophysiologically from conventional atherosclerotic lesions $[7,10]$.

Retrograde administration of cardioplegic solution through the coronary sinus was proposed to prevent the occurrence of ICAS, and, in case of occurence, percutaneous coronary intervention has become an alternative treatment option over coronary bypass surgery, avoiding the risks of early reoperation $[8,11]$.

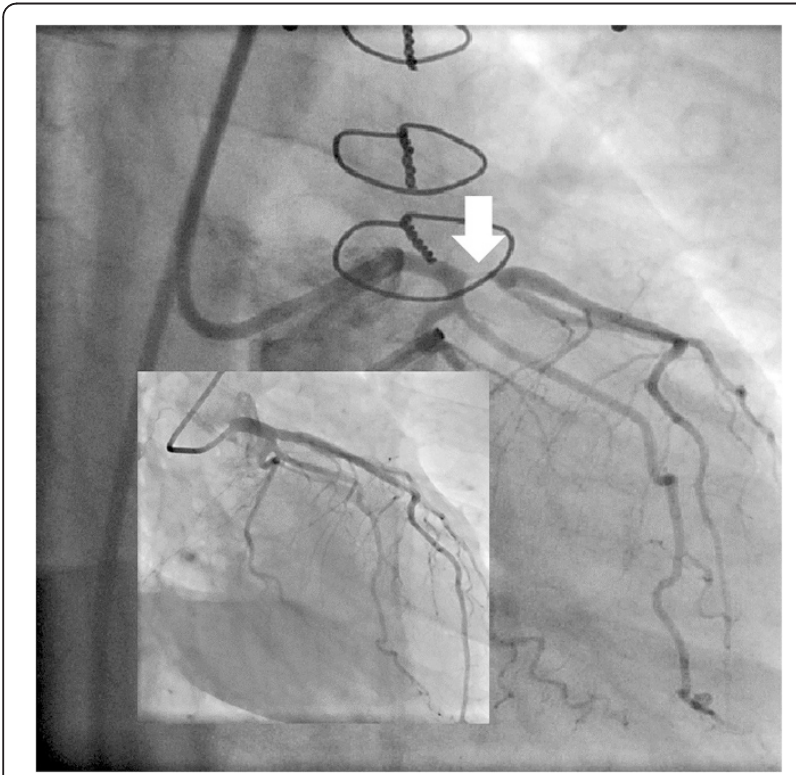

Figure 3 Subtotal ostial occlusion of the left anterior descending artery (RAO caudal view). Insert: preoperative coronary angiography.

\section{Conclusion}

Suspicion of iatrogenic coronary artery stenosis early after aortic valve replacement should lead to prompt invasive management in patients presenting with unstable angina pectoris and dynamic ECG-changes, whereas cardiac computed tomography could be the next diagnostic step in the absence of dynamic ECG-changes, especially if cardiac markers are negative. Pseudonormalization can

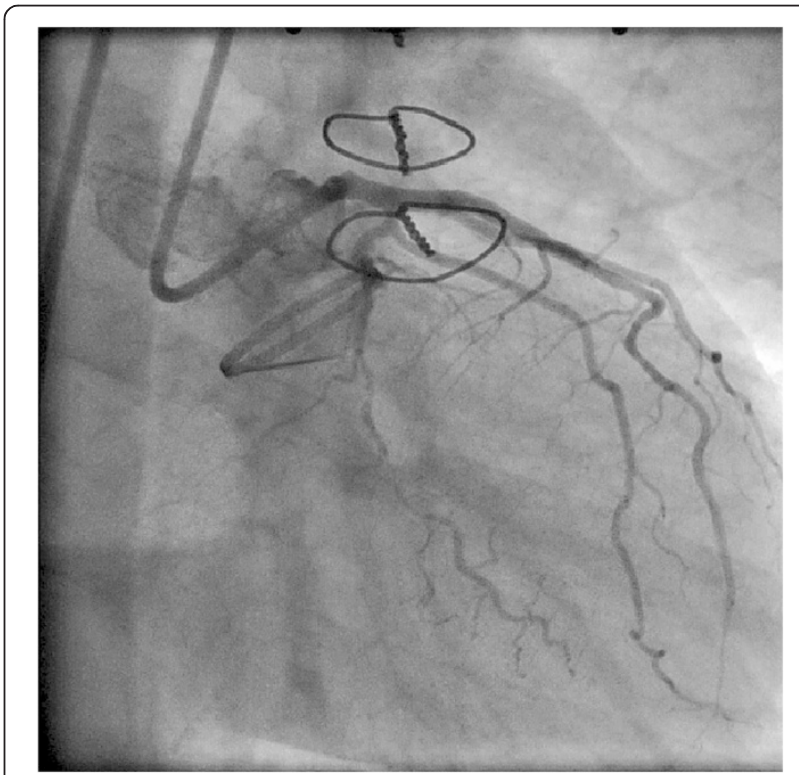

Figure 4 After percutaneous coronary intervention (RAO caudal view). 
mask otherwise obvious pathological T-waves when ECG is recorded during acute chest pain and is a potential diagnostic pitfall.

\section{Consent}

Written informed consent was obtained from the patient for publication of this case report and any accompanying images. A copy of the written consent is available for review by the Editor-in-Chief of this journal.

\section{Abbreviations}

AVR: Aortic valve replacement; ICAS: latrogenic coronary artery stenosis.

\section{Competing interests}

The authors declare that they have no competing interests.

\section{Authors' contributions}

SS was the main author and submitted the manuscript. HB was involved in data collection. CG was the surgical consultant, was involved in analysis and interpretation. JK was the cardiology consultant and revised the manuscript. CS was the cardiology consultant and gave final approval of the manuscript. All authors have read and approved the final manuscript.

\section{Acknowledgements}

None.

\section{Author details}

${ }^{1}$ 1st Medical Department - Cardiology, Linz General Hospital, Johannes Kepler University School of Medicine, Krankenhausstrasse 9, 4020 Linz, Austria. ${ }^{2}$ Department of Cardiothoracic Surgery, Linz General Hospital, Johannes Kepler University School of Medicine, Krankenhausstrasse 9, 4020 Linz, Austria.

Received: 24 October 2014 Accepted: 11 March 2015

Published online: 21 March 2015

\section{References}

1. Noble RJ, Rothbaum DA, Knoebel SB, McHenry PL, Anderson GJ. Normalization of abnormal T waves in ischemia. Arch Intern Med. 1976;136:391-5.

2. Simons A, Robins LJ, Hooghoudt TE, Meursing BT, Oude Ophuis AJ. Pseudonormalisation of the T wave: old wine? Neth Heart J. 2007;15:257-9.

3. Hanna EB, Glancy DL. ST-segment depression and T-wave inversion: classification, differential diagnosis, and caveats. Cleve Clin J Med. 2011;78:404-14.

4. Sethi GK, Scott SM, Takaro T. latrogenic coronary artery stenosis following aortic valve replacement. J Thorac Cardiovasc Surg. 1979;77:760-7.

5. Ulucan C, Yavuzgil O, Kayikçioğlu M, Can L, Payzin S, Kültürsay H, et al. Pseudonormalization: clinical, electrocardiographic, echocardiographic, and angiographic characteristics. Anadolu Kardiyol Derg. 2007;7:175-7.

6. Zack PM, Aker UT, Kennedy HL. Pseudonormalization of T-waves during coronary angioplasty. Cathet Cardiovasc Diagn. 1987;13:191-3.

7. Khan MA, Prati F, El-Omar M. latrogenic coronary ostial stenosis of left main stem following aortic valve replacement: visualization with optical coherence tomography. Cardiovasc Revasc Med. 2013;14:299-301.

8. Ziakas AG, Economou FI, Charokopos NA, Pitsis AA, Parharidou DG, Papadopoulos Tl, et al. Coronary ostial stenosis after aortic valve replacement: successful treatment of 2 patients with drug-eluting stents. Tex Heart Inst J. 2010;37:465-8.

9. An Y, Tamita K, Furukawa Y. latrogenic coronary artery stenosis at the ostium of left anterior descending artery after aortic valve replacement: a case report with imaging and histological findings. J Invasive Cardiol. 2010;22:E206-8.

10. Funada A, Mizuno S, Ohsato K, Murakami T, Moriuchi I, Misawa K, et al. Three cases of iatrogenic coronary ostial stenosis after aortic valve replacement. Circ J. 2006;70:1312-7.

11. Raja Y, Routledge HC, Doshi SN. Coronary stenting for iatrogenic stenosis of the left main coronary artery post-aortic valve replacement: an alternative treatment? Eur J Cardiothorac Surg. 2011;39:398-400.

\section{Submit your next manuscript to BioMed Central and take full advantage of:}

- Convenient online submission

- Thorough peer review

- No space constraints or color figure charges

- Immediate publication on acceptance

- Inclusion in PubMed, CAS, Scopus and Google Scholar

- Research which is freely available for redistribution 